\title{
The Use of LOM, SEM, FIB and APT to Clarify the Sequences of Failure of a Hot Dip Galvanized Structural Steel Section
}

\author{
Michael Panzenböck ${ }^{1}$ and Caroline Freitag ${ }^{1}$ \\ 1. Department of Physical Metallurgy and Materials Testing, Montanuniversität Leoben, Austria
}

Structural hollow profiles are widely used for steel constructions. To protect such profiles against corrosion, normally they are hot dip galvanized. In this case of failure, a broken support of a staircase was detected. The used hollow profile $(150 \times 150 \times 8 \mathrm{~mm}$, material S355J0) depicted in Figure 1 contains a crack located at one corner and extending over the whole profile length (approx. $6 \mathrm{~m}$ ). As can be seen from Figure 1 there is a certain distance between the crack flanks. After cutting out the fracture sections, the parts show a distinct curvature (Figure 2a). From this can be concluded that residual stresses in circumferential and longitudinal directions are prevalent.

Figure $2 \mathrm{~b}$ reveals a heavily corroded fracture surface. No features are visible in detail. After a cleaning with citric acid many cracks starting from the inside (red arrows in Figure 2c) become detectable. A macroscopic inspection reveals exclusively a brittle fracture surface. No plastic deformation is detectable. Metallographic investigations carried out at the outer surface, show a zinc layer with cracks in it (Figure 3 ). In contrast to this, huge cracks $(150-300 \mu \mathrm{m}$ of length) and very fine cracks beneath the cracks of the zinc layer are visible at the inner surface and only within the bend (Figure 4). After opening the crack shown in Figure 4 at room temperature, different fracture features within the steel are visible (Figure 5). At first, an intergranular damage is prevalent resulting from LME (Liquid Metal Embrittlement). This can be confirmed by FIB-investigations. The grain boundaries are covered with zinc (see insert in Figure 6). LME can be a result of copper and tin segregations at grain boundaries [1], which can be detected by APT. The transgranular fracture can be attributed to hydrogen induced stress corrosion cracking, where the hydrogen is a result of the cathodic reaction $[2,3]$. The ductile fracture originates from the forced rupture at room temperature. A possible sequence of the damage process is given in Figure 7 (see legend).

\section{References:}

[1] M. Panzenböck et al, Practical Metallography 53(10) (2016), p. 641.

[2] M. Pohl, Practical Metallography 51(4) (2014), p. 291.

[3] A. Luithle, PhD. Thesis, Ruhr University Bochum, Germany, (2013).

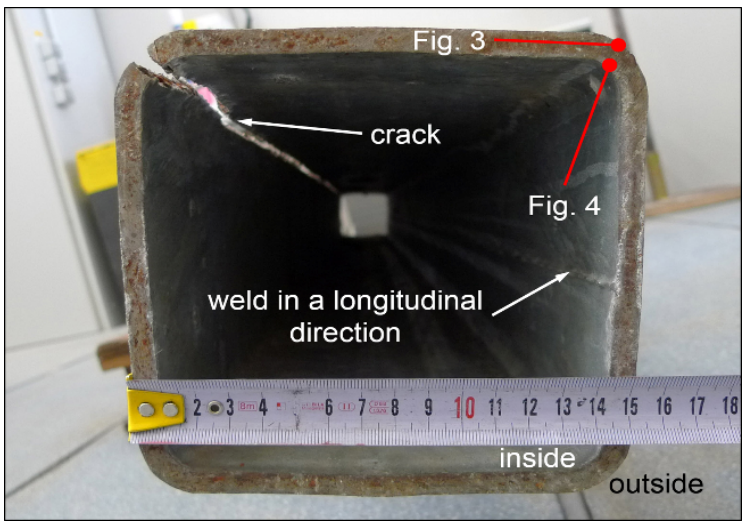

Figure 1. Overview of the structural steel section with a crack located at the upper left corner, growing in a longitudinal direction. The profile is closed by a weld during manufacturing by cold bending.

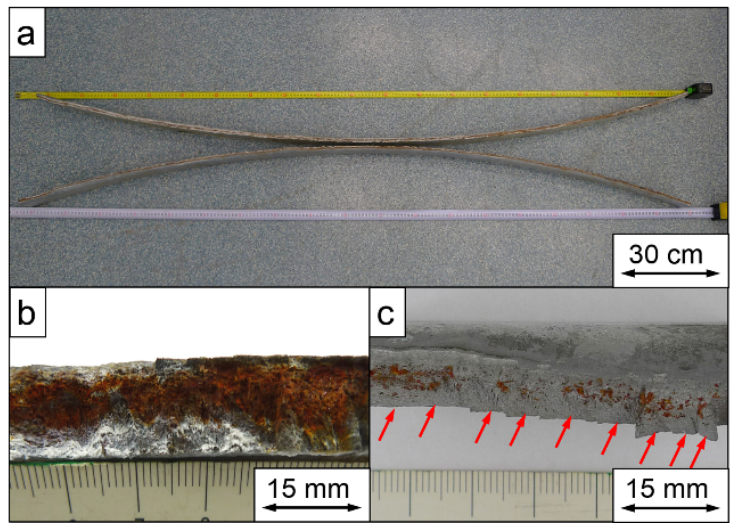

Figure 2. a) Cut out of the fracture sections. The bend of the parts reveal residual stresses in the longitudinal direction. b) Heavily corroded fracture surface. c) Cleaned fracture, the arrows indicate crack initiation at the inside of the profile. 


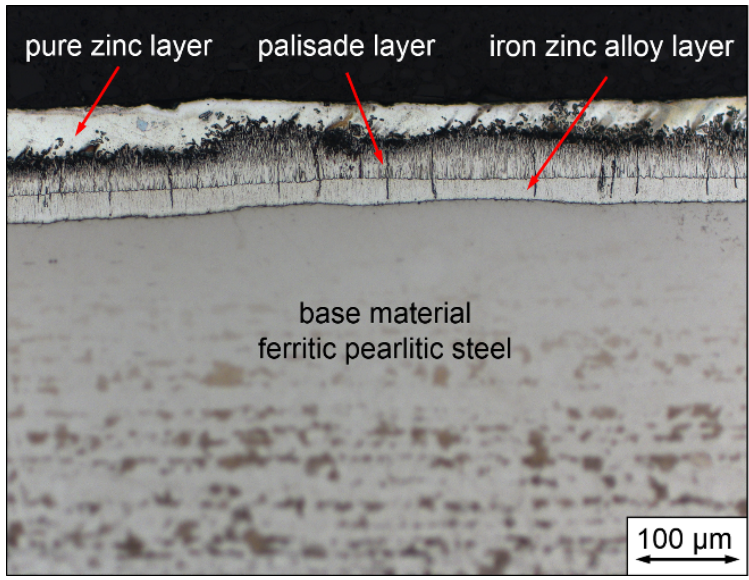

Figure 3. Light optical micrograph of the zinc layer and the steel after etching with nital at the outside of a corner. Crack arrest takes place within the iron zinc alloy layer.

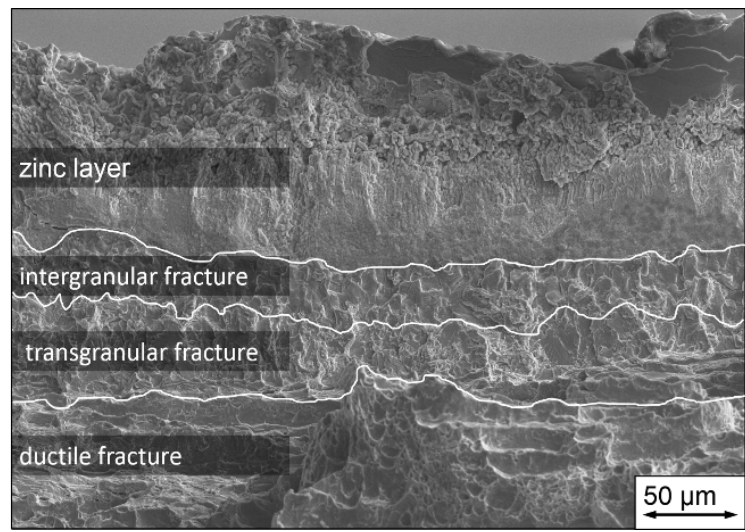

Figure 5. SEM micrograph of the fracture surface after opening the crack shown in Fig. 4 at room temperature. It is possible to distinguish between brittle fracture features and the ductile rupture at room temperature.

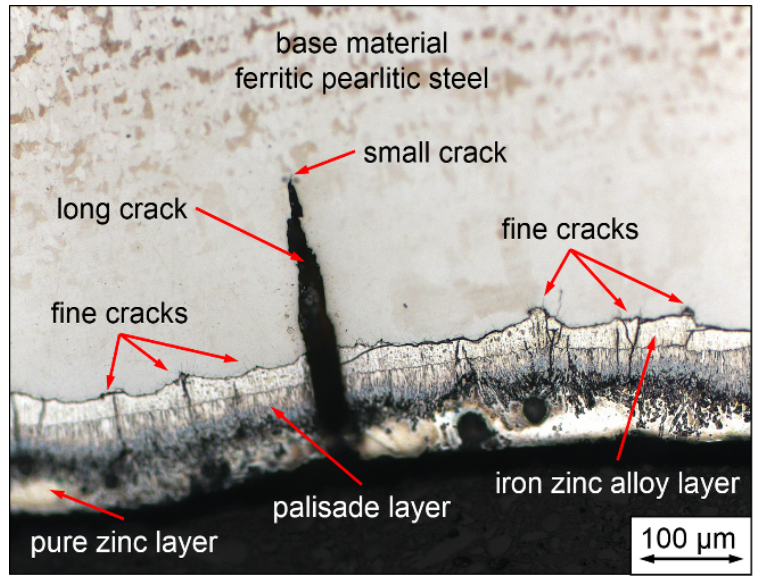

Figure 4. Light optical micrograph of the zinc layer and the steel after etching with nital at the inside of a corner. No crack arrest. The red arrows indicate fine cracks.

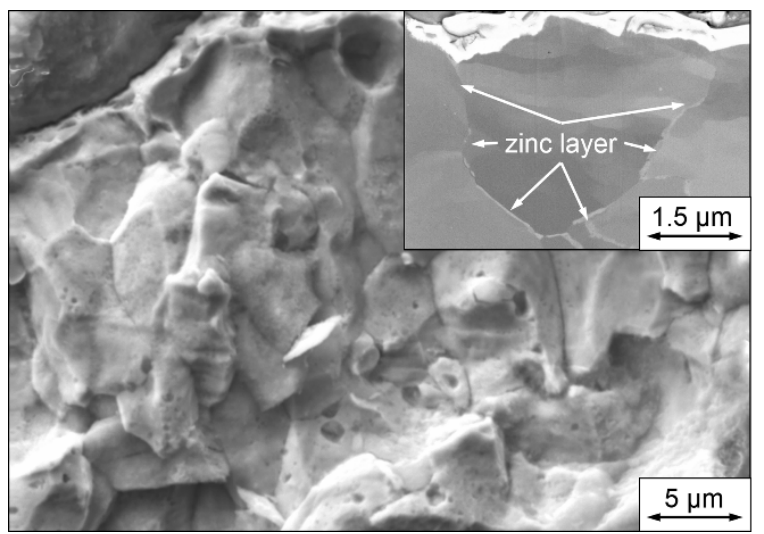

Figure 6. SEM micrograph, detail of Fig. 5. Intergranular fracture of the steel material beneath the zinc layer. The grains are covered with a zinc layer (see insert), caused by LME during the process of hot dip galvanization.

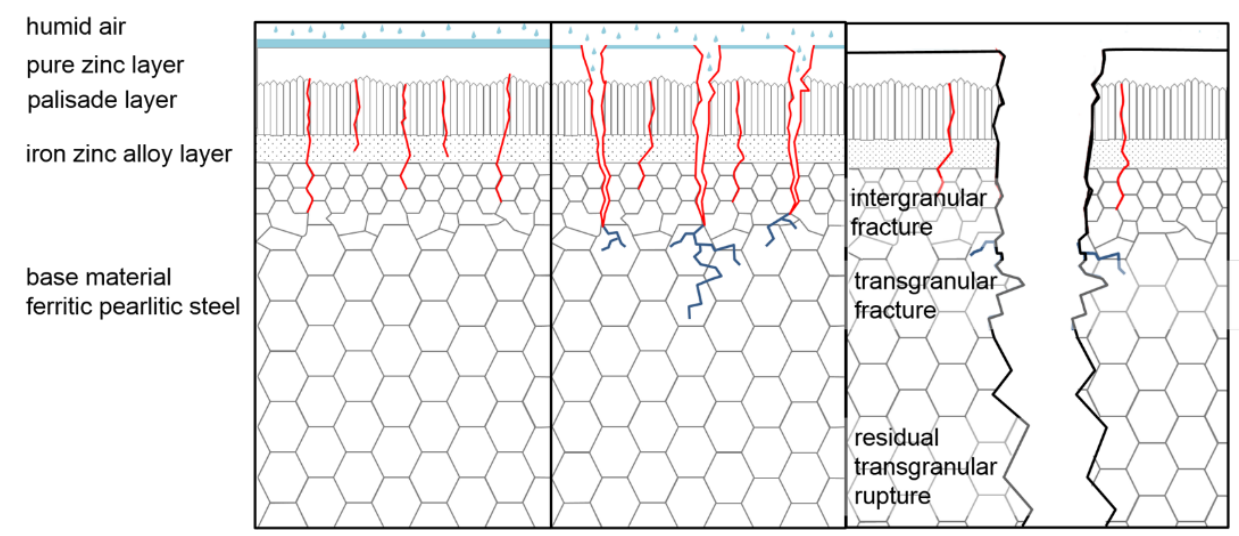

Figure 7. Schematic drawing of the sequences of damage. Left: Inside cracks at the corner are prevalent due to LME. Middle: Humid air and/or condensed water forces corrosion attack and leads to hydrogen induced stress corrosion cracking. Right: Deep temperatures, residual stresses and a low toughness of the structural steel are responsible for the brittle transgranular rupture. 